\title{
A ABORDAGEM REFLEXIVO-DIALÓGICA NA FORMAÇÃO DE FORMADORES ON-LINE: POSSIBILIDADES E DESAFIOS
}

\author{
Lina Cardoso Nunes* \\ Mirian Garfinkel
}

\begin{abstract}
RESUMO
O presente artigo aborda as peculiaridades e diferentes estratégias que o mundo on-line requer na práxis cotidiana transitando por conceitos como cibercultura, interatividade, hipertexto, autonomia, entre outros. Assim sendo, a formação de formadores precisa se voltar para uma perspectiva dialógico-reflexiva capaz de estimular vínculos que facilitem a construção de redes de conhecimento e saberes. São de inestimável valor as contribuições teóricas de Freire, Habermas, Bakhtin, Buber, Shon e Levy. O espaço para que a educação on-line, não a instrução on-line, atinja a sua plenitude precisa estar em sintonia com o saber saber, saber fazer e saber aprender.
\end{abstract}

PALAVRAS-CHAVE: Cibercultura. Formação de formadores. Perfil dialógico-reflexivo.

\begin{abstract}
This paper broaches the peculiarities and different strategies the on-line world requires to make possible a daily "práxis" reflecting

Professora do Curso de Graduação em Pedagogia e do Mestrado em Educação da Universidade Estácio de Sá. Doutora em Educação pela Universidade Federal do Rio de Janeiro.

** Professora de Psicopedagogia Institucional do curso de Pós-Graduação da Universidade Estácio de Sá. Mestre em Educação pela Universidade Estácio de Sá.
\end{abstract}


concepts as cyberculture, interactivity, hypertext, autonomy, among others. Therefore, the development of the formers needs to turn forward to a dialogic-reflexive perspective able to stimulate links that expedite building nets of knowledge. Theoretical contributions of authors such as Freire, Habermas, Bakhtin, Benjamim, Buber, Shon and Levy are of inestimable value.

The space where education on-line, instead of instruction on-line, will be able to reach plenitude has to be connected with "know to know, know to do and know to learn".

KEYWORDS: Cyberculture. Formers of formation. Dialoguic reflexive profile.

\section{A abordagem reflexivo - dialógica na formação de formadores}

A realidade sócio-econômica-cultural vem apontando para a necessidade de constante, tendo em vista a quantidade de novos saberes que vinculam sujeito e ciência e que num primeiro momento pode levar a se pensar em uma ciência ajustada aos interesses dos que pesquisam, ou seja, ciências entendidas como profissionalizantes que vão perdendo intimidade com o saber, passando aos poucos a ser ficção, afastando-se do seu objeto, já que segundo Benjamin (1984, p.32):

[...] o nome da ciência se presta por excelência a ocultar uma arraigada e comprovada indiferença. Medir a vida estudantil com a idéia de ciência, não significa de maneira alguma panlogismo ou intelectualismo [...]. Para a grande maioria dos estudantes a ciência é uma escola profissionalizante sendo assim, ela deve reger, exclusivamente, a vida de quem a segue $[\ldots]$.

A mundialização com seus inúmeros desdobramentos, no que diz respeito ao mercado de trabalho, enfatiza a inclusão do maior número de pessoas familiarizadas com o mundo alfabetizado, assim

Educ. e Filos., Uberlândia, v. 20, n. 39, p. 13-38, jan./jun. 2006. 
como resgate de outro tanto, por intermédio da educação continuada, ou, usando uma linguagem mais ao gosto da política neoliberal, adequada.

Isso se traduz no advento em maior escala da utilização do recurso Educação à Distância - EAD, na modalidade on-line, utilizando a tecnologia midiática, cujo objeto do desejo é um computador, computador esse "pilotado" por um sujeito, cuja formação é a principal preocupação deste trabalho.

Em Adorno (1995, p.69) a palavra formação tem o sentido de Bildung, vinculado a uma especificidade do campo cultural, assim descrita por Abbagnano (2000, p.470):

[...] formação (alemão Bildung) no sentido específico que esta palavra assume em filosofia e pedagogia, em relação com o termo alemão correspondente, indica o processo de educação ou de civilização, que se expressa nas duas significações de cultura; compreendida de um lado como educação, de outro lado como sistema de valores simbólicos.

Neste contexto, uma prática afastada do embasamento filosófico, corre o risco de se esvaziar por não conseguir a mediação entre o fazer e o saber, o que enfatiza a importância da formação no sentido de Bildung.

No específico campo da EAD on-line, evidencia-se a necessidade de um constructo norteado pela clareza de uma estratégia que transita no espaço do pensar e se apropriar do que tiver significância para seu Eu, para sua práxis, já que "a natureza, compreendida e dominada pela ciência [...] mantém e melhora a vida dos indivíduos e ao mesmo tempo os submete aos senhores do aparelho" (HABERMAS, 1968, p.51), sendo capaz de acelerar ou retardar o processo de construção do conhecimento. Portanto, o saber refletido e desenvolvido por meio de metacognição e em diálogo constante entre a realidade dos fatos evidencia a possibilidade de gerar soluções equilibradas, ou ainda, segundo Benjamin (1984, p.32) a "ciência pela sua essência não admite solução por si própria; ela obriga o pesquisador a ser sempre professor [...]". 
Assim, "enquanto universo de meios, a técnica tanto pode debilitar como aumentar o poder do homem. No estágio presente, o homem é talvez mais impotente do que nunca perante seu próprio aparelho" (HABERMAS, 1968, p.54). Isto se reproduz no mercado de trabalho. Segundo Shön (2000, p.37) "as pessoas que exercem uma profissão são diferentes entre si [...] trazem para seu trabalho um corpo de conhecimento profissional, explícito de um sistema apreciativo", referente a um conjunto de valores, preferências e normas através dos quais pretendem validar as decisões tomadas.

Quando se trata de formação de formadores é importante articular o conteúdo e a prática, mediando teoria e ação pedagógica e desenvolver a capacidade de identificar tanto "situações nãofamiliares como familiares" (SHÖN, 2000, p.63), criando-se a partir destes pressupostos um curso flexível.

Importante não é apenas ver e fazer; é necessário identificar uma "nova possibilidade de agir" (SHÖN, 2000, p.63), que favoreça a ação criativa e adequada. Nesse contexto, "a reflexão-na-ação envolve, necessariamente, experimento" (SHÖN, 2000, p.63), experimento esse que pretende criar condições de identificar claramente a(s) consequiência(s) resultante(s) da ação. A fim de relacionar a proposição acima com o assunto em pauta, cabe um olhar sobre a instituição escola e quais os procedimentos comumente utilizados.

A instituição escola, historicamente, é pouco sensível às mudanças, mas esforça-se por entendê-las, pois percebe as possibilidades e as perspectivas que decorrem deste movimento, para todos os envolvidos no processo. Cabe enfatizar que as mudanças não se referem apenas à aquisição e manutenção de equipamentos telemáticos, mas a capacidade de reformular os objetivos deste espaço, digo, ambiente de aprendizagem, para ser fiel à nomenclatura do mundo digital. Em vista disto, o que se encontra no campo? Até o momento, os desafios estão na cabeça de muita gente, no plano das idéias, enquanto a prática retoma o velho e cansado caminho dos conteúdos.

O esforço, o trabalho, o investimento no estudar e no aprender são sonhos que se pretende atingir, como se fosse um sorteio, do

Educ. e Filos., Uberlândia, v. 20, n. 39, p. 13-38, jan./jun. 2006. 
qual participa pequeno número de privilegiados, gerando, por sua vez, um reduzidíssimo número de ganhadores. O desafio de estudar, que Freire (1979, p.41) define como "um que fazer exigente em cujo processo se dá uma sucessão de dor, prazer, sensação de vitórias, de derrotas, de dúvidas e de alegrias", é uma ação que requer muita disciplina forjada internamente, "em nosso corpo consciente" (FREIRE, 1979).

Nesta linha de raciocínio, a escola ainda é um espaço capaz de responder a questionamentos dos aprendentes, como também à sua curiosidade, desafiada minuto a minuto por educadores comprometidos com o desenvolvimento do cidadão e da cidadania. O plano de trabalho de cada educador passa a ser um convite à parceria e à construção conjunta entre elementos capazes de administrar tempo, autonomia, livre arbítrio e saberes. Esta, a nosso ver, seria uma regra básica para a práxis de formadores em cursos on-line.

A realidade, porém, é outra! Na maioria dos casos o "pacote/ curso" vem fechado, os saberes constituídos, e, um tempo enorme é dedicado a imprimir material gráfico, o que faz os envolvidos desenvolverem habilidades de impressão nas frágeis máquinas caseiras, com poucos recursos para produzir apostilas de 50 a 60 páginas a serem estudadas, obviamente, bem longe das emoções descritas por Freire anteriormente!

A redimensão do espaço-tempo é fundamental. A escola é "ainda fortemente marcada pela disciplinaridade, dificilmente preparando-se para viver a complexidade do mundo atual" (ALARCÃO, 2001, p.18). Esse aspecto sinaliza para uma "práxis" que visa desenvolver auto-disciplina, auto-avaliação, assim como disponibilidade pessoal dos que se envolvem em cursos on-line, que não requerem regulação externa, muitas vezes, realizada através de barulhentas campainhas ou zelosos inspetores, a lembrar os alunos constantemente de suas obrigações.

No entanto, a tradição ocidental comprometida com o desenvolvimento do pensamento lógico-matemático e da razão, "não potencializa o desenvolvimento global do ser/pessoa, facilmente discrimina e perde os que não se adaptam ao

Educ. e Filos., Uberlândia, v. 20, n. 39, p. 13-38, jan./jun. 2006 
paradigma" (ALARCÃO, 2001, p.19). Emerge, assim, um modelo de educação, aparentemente comprometido com a mudança. Só que a plenitude deste termo supõe mudança "não apenas nos currículos [...], mas na organização disciplinar, pedagógica, organizacional [...]" (ALARCÃO, 2001, p.19), e que, como processo, vai se realizando lentamente, ao sabor da vontade política nacional [...].

Em realidade, mudança significa ação, que Shön (2000) entende como parte do binômio, palavra - ação. Sua proposta gira em torno de um processo de transição em que "a convergência de significado, fica evidente na facilidade com que os participantes costumam entender-se, terminando as sentenças um do outro [...]" (SHÖN, 2000, p.127). Contudo, para que isto se torne real é necessário conjugar esforços daqueles "que a fazem - juntando-se em um empreendimento comunicativo específico, um diálogo de palavras e ações" (SHÖN, 2000, p.127).

O autor em foco descreve como funciona esse diálogo: os atores "[...] transmitem mensagens um ao outro, não apenas, em palavras, mas também através de performance"; o estudante tenta fazer o que está aprendendo, revelando, assim, o que entendeu, como também o que não foi entendido. "O instrutor responde com conselho, crítica, explicação, descrições e também com sua própria performance" (SHÖN, 2000, p.128).

Configura-se a vigência de um diálogo constante entre as partes, que tem como resultado a reflexão-na-ação recíproca: "o estudante reflete sobre o que escuta o instrutor dizer, ou, o vê fazer e também reflete sobre o conhecer-na-ação [...]" (SHÖN, 2000, p. 128). Estamos no terreno dos diálogos, em que as partes "devem começar a fazer a transição de um estágio anterior de confusão, mistério e incongruência para um estágio mais avançado de convergência de significado [...]", decodificando discursos e ações de cada um para que vá tomando corpo o aprender a aprender. É a dimensão dialógica do processo.

Para que o diálogo não sofra solução de continuidade, o trabalho comunicativo do diálogo, "não depende apenas da habilidade do ensinante e aprendente de cumprir seus papéis, mas

Educ. e Filos., Uberlândia, v. 20, n. 39, p. 13-38, jan./jun. 2006. 
da vontade de fazê-lo (grifo nosso). Aqui estão envolvidos sentimentos, bem como idéias, cada um criticamente ligado ao outro" (SHÖN, 2000, p.130).

$\mathrm{O}$ núcleo da questão se faz visível. $\mathrm{O}$ envolvimento de sentimentos e idéias afasta a possibilidade cartesiana do ensinante falar e o aprendente ouvir; do saber ser incontestável, verdade única; o aprendente está sendo chamado para dentro do monólogo para torná-lo diálogo, para entender-se autor e ocupar um espaço vazio em parceria com o Outro.

O diálogo entre Habermas e Shön se configura. O filósofo da Escola de Frankfurt, assim se reporta à Teoria da Ação Comunicativa (FREITAG, 1962, p.109): [...] já sugeri que abandonássemos o paradigma da filosofia da consciência, voltando-nos para uma teoria da interação. Isso implica em abandonar o conceito monológico da razão e defender um conceito de razão comunicativa, dialógica, que, por sua vez, pressupõe a idéia do sujeito epistêmico. Na teoria da ação comunicativa ele é substituído pelo grupo.

Diálogo, grupo, coletivo e linguagem são novos parâmetros. A ação comunicativa, um passo à frente na construção do cotidiano emancipado, "se refere à interação de ao menos dois sujeitos capazes de linguagem e ação, que entabulam uma relação interpessoal" (FREITAG, 1962, p.109).

Completa o parâmetro de comunicação um novo ingrediente: a ética, que através do resgate de valores, reflexão e debate favorece o desenvolvimento da cidadania. A escola inovadora assume um projeto próprio; liderança, racionalidade dialógica, pensamento sistêmico e articulação político-administrativo-curricular passam a ser os "pilares de sustentação de uma organização dinâmica, situada, responsável e humana" (ALARCÃO, 2001, p.20).

Entenda-se esta instituição que pulsa, que vibra, que chora e se frustra constituída de pessoas que se relacionam entre si, com seu trabalho, onde: 
[...] o desenvolvimento dos homens tem lugar através de um agir próprio e consciente de seu objectivo, agir esse que é determinado apenas por aquela objectividade social com a qual, enquanto já acabada e pronta, os homens se deparam e a qual, na qualidade de natureza, impõem limites ao agir dos mesmos (HABERMAS, 1990, p.87).

Esses itens fundamentais são o roteiro às nossas reflexões, na medida que, "a formulação (acima) não exprime de modo suficientemente claro que a perspectiva de emancipação não resulta de modo nenhum do paradigma de produção, mas sim do paradigma do agir orientado no sentido do entendimento mútuo" (HABERMAS, 1990, p.87). Portanto, a educação à distância (EAD) é uma das inúmeras alternativas de que dispõem os educadores na tarefa social e política de incluir todos na cultura digital e no contexto do que chamamos de inteligência artificial, da passagem do analógico para o digital. Só que por falta de intimidade com a tecnologia digital, o formador parece criar fantasmas assustadores, preferindo, por desconhecimento no mais das vezes, se afastar deste ambiente. Essa circunstância lembra o fato de que quem criou o alfabeto, com certeza era analfabeto, ou como dizia Bakhtin (1992, p.367): "os gregos antigos ignoravam o essencial de si mesmos; não sabiam que eram antigos e jamais se denominavam assim". Ante esta situação vale identificar no magistério um imaginário que, em vez de servir de mola propulsora, paralisa, mantendo toda uma classe a reboque de inovações, com importante repercussão em seu ambiente de trabalho, que deve focar uma prática dialogal dialógica, orientada pela interatividade, interagindo por meio da rede:

[...] construída para além e para fora da mente individual, uma enorme e complexa rede que amplia e imita a rede da consciência subjetiva: passamos a ser, desta vez, nós mesmos elos de uma grande cadeia polifônica que é composta de mentes e sujeitos conectados, capazes de dialogar entre si, construindo um pensamento que flui e se dispersa,

Educ. e Filos., Uberlândia, v. 20, n. 39, p. 13-38, jan./jun. 2006. 
insustentável e irrefreável, por entre os fios da trama em que é tecido um texto do tamanho do próprio mundo (RAMAL, 2002, p. 101).

Eis a realidade de agora: o risco de exclusão já não é mais agente de mão única, e sim, de mão dupla; tanto vale para aquele que ensina, quanto para o que aprende. De acordo com Ramal (2002, p.254):

[...] o saber passa a ser construído coletivamente; as diversas competências dos estudantes são reconhecidas e desenvolvidas, de forma a se integrarem melhor na grande árvore da inteligência coletiva de cada grupo [...]. Por conhecerem a beleza dessa realidade polifônica, crianças e adultos começam a não mais suportar comunidades excluídas da dinâmica social.

Há uma nova dimensão de pensar e agir, que pede novas competências e saberes do educador/formador, o qual Ramal (2002, p.191) denomina "arquiteto cognitivo". Seu papel não é mais de transmissor de conhecimento:

[...] o arquiteto cognitivo é: (a) um profissional; (b) capaz de traçar estratégias e mapas de navegação que permitam ao aluno empreender, de forma autônoma e integrada, os próprios caminhos de construção do (hiper) conhecimento em rede; (c) assumindo, para isto uma posição consciente de reflexão-na-ação; (d) fazendo um uso crítico das tecnologias como novos ambientes de aprendizagem.

Ao formador cabe conjugar o papel de arquiteto cognitivo e de dinamizador da inteligência coletiva, em que "procura potencializar o hipertexto mental e [...] ajudar a responder ao desafio das redes a serem criadas entre grupos, escolas e sistemas educacionais" (RAMAL, 2002, p.190). Já agora, este sujeitoformador é responsável por preparar os caminhos que levam ao

Educ. e Filos., Uberlândia, v. 20, n. 39, p. 13-38, jan./jun. 2006 
aprender a aprender, por meio de um currículo não mais segmentado, e sim, pleno de hipertextos, sem se esquecer de que a mente humana tem memória, com capacidade de aceitar todos os tipos de erro e acerto, enquanto o computador, não! Aqui se retoma a dimensão subjetiva do indivíduo e o compromisso de "ajudar o homem a organizar reflexivamente o pensamento" (FREIRE, 1981, p.67). Sendo crítico, pretende-se que seja coerente, "inserindo-se no processo histórico, [quando] renunciará ao papel de simples objeto e exigirá ser o que é por vocação: sujeito" (FREIRE, 1981, p.68).

No entanto, o campo da criação humana é infinito; assim como é capaz de criar uma burocracia que, nos seus mínimos detalhes, vai mantê-lo refém em sua própria rede, é capaz de criar as soluções para que se livre da mesma, bastando agir de acordo com suas habilidades cognitivas e afetivas. Contudo, está prestes a travar um confronto entre sua formação livresca e solitária e uma cultura que está a exigir relacionamento entre todos os participantes. São novos tempos. Tempos de inteligência coletiva, redes de aprendizagem. Tempos de aprendizagem colaborativa, facilitadora da emergência de vínculos que as conexões e links vão forjando através dos e-mails. Tempo de se apropriar dessa prática, através de sua experiência e, além disso, por gosto, acreditar que esta estratégia pode ser importante para todos os aprendentes...

Nesta perspectiva, a educação on-line necessita configurar objetivos e definir uma didática, capaz de propiciar a criação de ambientes de aprendizagem dialógicos que favoreçam a reflexão e a identificação dos diferentes estilos de aprendizagem. O corolário desta afirmação vai acontecer, na medida em que cada escola formule seu projeto, capaz de atender às necessidades da comunidade local, inserido num espaço que abrange todos que estão sob sua ação-reação, utilizando ferramentas que facilitem a problematização da realidade, e conseqüentemente a busca de soluções.

A concepção democrática define o caminho pedagógico que à medida que se despe da preocupação em selecionar, se aproxima dos cuidados com o ensinar e aprender de todos, reconhecidas as 
suas diferenças e dificuldades já que, segundo Bourdieu, a ação pedagógica se faz sentir através da imposição de normas culturais (1992, p.51) e "tende sempre a modificar os comportamentos, os afetos, as representações dos educandos [...] com uma representação prevista anteriormente".

Estamos lidando com o que cada um pressupõe que o outro tenha, um código aplicável a cada texto enunciado. Assim, cada qual imagina que o outro conheça as leis do discurso que estão sendo usadas para identificar o professor/ formador nos cursos on-line. Nesse sentido, merece decodificação o termo educação on-line no universo da educação à distância. Em realidade, a educação à distância vem sendo praticada há muito no Brasil através de correio, do rádio (Projeto Minerva), da televisão (Telecurso, 2000). O diferencial está no computador, adotado na EAD, como ferramenta. Vale esclarecer que de acordo com Papert (1994, p. 143),

[...] uma classificação um pouco diferente foi utilizada com freqüência - e cujo autor original eu não consegui identificar - fala sobre "aprender com o computador, aprender do computador e aprender sobre o computador". O termo com corresponde nitidamente à ferramenta e do, ao tutor. O relacionamento entre sobre e pupilo é menos direto, mas ainda existe, no sentido de que ser capaz de programar um computador é sinônimo de aprender mais profundamente sobre como ele funciona do que é necessário através dos outros modos de uso.

Aqui se identifica a interseção da Escola de Frankfurt, com a prática reflexiva e os fundamentos freirianos. A convergência se dá quando da relação da capacidade de leitura do mundo, de conhecimento significativo e da perspectiva deste sujeito que, em ambientes infopobres, quer analógica, quer digitalmente, é identificado como analfabeto funcional, produzido com "a sem cerimônia" de projetos que começam sem data de acabar, de avaliações apresentando resultados duvidosos e uma quase nenhuma reflexão sobre as práticas. 
Nesse universo o investimento em compra de computadores para uso em unidades educacionais é inversamente proporcional ao investimento em alfabetização e letramento, não só nas novas gerações como nos milhares de cursos de educação continuada, nem sempre adequada; o entendimento do texto dificilmente se concretiza em práticas de digitação realizadas em cursos de informática. Interagir com o texto é necessário para que o sujeito seja capaz de apropriar-se de seu conteúdo. Estamos frente a algo maior que a digitação, algo como cultivar o hábito de leitura para poder navegar no "oceano de informações" (SILVA, 2003 a, p.21).

Para aqueles que têm maior intimidade com o texto escrito, fica a possibilidade de um infinito número de janelas que se abrem quando da utilização da rede mundial de computadores e o desafio de ser capaz de selecionar criticamente o que é de seu real interesse. Porém, como ficam os analfabytes e os infopobres, já que fica proibido imaginar que estes personagens estão restritos ao espaço do imaginário?

Assim, defronta-se esse ambiente com a questão da inclusão/ exclusão, que limita a participação de aprendentes e ensinantes, alienando-os da participação no mundo da educação on-line e que requer que cada um dos participantes do processo seja alfabetizado tecnologicamente e que segundo Sampaio e Leite (1999, p.75) consiste "no domínio contínuo e crescente das tecnologias que estão na escola e na sociedade, mediante o relacionamento crítico com elas". E se assumir educador/formador capaz de "lidar com as diversas tecnologias, interpretando sua linguagem e criando novas formas de expressão, além de distinguir como, quando e por que são importantes e devem ser utilizadas no processo educativo" (SAMPAIO e LEITE, 1999, p.75). Sua capacidade de comunicação e interação é posta à prova. Já se exige mais do que apenas a habilidade técnica. Mais do que nunca, o espaço de aprender a aprender, quer geograficamente delimitado na sala de aula, quer estabelecido por vias midiáticas, precisa ser um espaço democrático que reconheça o tecido sócio-econômico-cultural em que está inserido e caminhe em parceria, compartilhando, questionando e discutindo todo o tempo.

Educ. e Filos., Uberlândia, v. 20, n. 39, p. 13-38, jan./jun. 2006. 
É chegada a hora dos que estão incluídos no ambiente acadêmico entender que estamos frente a um "boom" de educação superior popular, recebendo sujeitos de diferentes procedências estimulados a retornar aos bancos escolares. Ao chegarem a essa posição, precisam desenvolver condições para permanência, com auxílio de todos envolvidos no sistema escolar. Expor as dificuldades que confirmam o gap de conhecimentos aclamados pela comunidade educativa apenas acelera o processo de exclusão dos que ainda precisam de tempo e vivências para interagir com a nova realidade definida por Levy (1998, p. 30):

[...] na era do conhecimento, deixar de reconhecer o outro em sua inteligência e recusar-lhe sua verdadeira identidade social é alimentar seu ressentimento e sua hostilidade, sua humilhação, a frustração de onde surge a violência. Em contrapartida, quando valorizamos o outro de acordo com o leque variado de saberes, permitimos que se identifique de um modo novo e positivo, contribuímos para mobilizálo, para desenvolver nele sentimentos de reconhecimento que facilitarão, conseqüentemente, a implicação de outras pessoas em projetos coletivos.

A ênfase de Freire (1999, p.23) em alertar quanto à formação de quem forma é sempre de salutar lembrança. Enumerar as condições necessárias a um educador/formador ou que outro nome tenha, nos remete ao que ele denomina no título do capítulo 1(um): "não há docência, sem discência" (FREIRE, 1999, p.23).

Nessa perspectiva, é oportuno remeter à importância da dimensão reflexiva, na escola reflexiva, que de acordo com Alarcão (2001, p.25) é uma "organização que continuadamente se pensa a si própria, na sua missão social e na sua organização", e que deveria desenvolver a ação comunicativa, capaz de criar situações de debate, troca de idéias, enfim tudo que leve a uma saudável construção de conhecimento. A ação comunicativa é, ainda segundo Habermas (1991, p.9), "a ação social em que os planos dos diferentes agentes seguem coordenados através de ações da

Educ. e Filos., Uberlândia, v. 20, n. 39, p. 13-38, jan./jun. 2006 
fala, em que os falantes pretendem inteligibilidade e verdade para o conteúdo do que dizem [...]" (tradução livre).

Na perspectiva de Alarcão (2001, p.25) "o EU que se conhece a si próprio e questiona a si mesmo é capaz de aprender, de recusar a tornar-se coisa e obter autonomia". Ao transferir essa postulação para a instituição-escola e para o ambiente digital é que se percebe o quanto é necessário trabalhar no sentido da formação de pessoas capazes de humanizar a máquina que "através de etapas de reflexão atinge um nível de progresso" (ARAGÃO, 1992, p.55).

Uma sociedade se emancipa por sua capacidade de criar processos de trabalho ao desenvolver condições de orientar os sujeitos para saberes tecnicamente aplicáveis, e, na sua construção, optar por instituições em que a interação social se institua. Segundo Aragão (1992, p.55) através de "uma comunicação isenta de dominação", cabendo agregar as palavras de Freire (1981, p.69): "não cria aquele que impõe, nem aqueles que recebem; ambos se atrofiam e a educação já não é educação [...]".

\section{A práxis reflexivo-dialógica em cursos on-line: apontando possibilidades e desafios}

De acordo com Levy (1993, p.17) "vivemos um destes raros momentos em que, a partir de uma nova configuração técnica, quer dizer, de uma nova relação com o cosmos, um novo estilo de humanidade é inventado" desafiando a pedagogia a se apropriar do mundo digital. $\mathrm{O}$ ensinar e o aprender têm novos parâmetros; há mudanças para todos os gostos. Um enorme volume de informações se encontra à disposição. Para lidar com isto, é necessário um sujeito crítico capaz de selecionar o que de mais importante se apresenta para a sua continuada construção do conhecimento:

[...] a partir do momento em que uma relação é inscrita na matéria resistente de uma ferramenta, de uma arma, de um edifício ou de uma estrada, torna-se permanente. Linguagem e técnica contribuem para produzir e modular o tempo. No 
entanto, a escrita, a oralidade e a digitalidade ocupam espaços diferentes, enquanto a linguagem oral detém a primazia de ser a forma mais elementar de comunicação (LEVY, 1993, p.76).

As passagens do Homem por diferentes estágios de linguagem remetem ao desenvolvimento de habilidades específicas, orgânicas e sociais. Desde a oralidade - em que o conhecimento de baseia na memória do que é passado de pai para filho - ao advento da escrita que desapropria a geração anterior do saber, à medida que já se encontra legitimado no papel, podendo ser consultado a qualquer hora, capaz até de "eliminar a mediação humana no contexto que adaptava ou traduzia as mensagens vindas de um outro tempo ou lugar" (LEVY, 1993, p.89).

A memória já tem um pouso; "o saber está lá disponível, estocado, consultável, comparável" (LEVY, 1993, p.95). Dando um salto no tempo estamos frente às máquinas cuja função é armazenar dados, usando uma tecnologia que vai se aprimorando na velocidade da luz. O computador é "a varinha de condão" para se entrar neste universo, universo este que "é constituído por uma infinidade de dispositivos materiais e camadas de programas que se recobrem e interfaceiam umas com as outras" (LEVY, 1993, p.101). A computação e seus derivados são o sinal dos tempos de globalização, de megalópoles, de correrias. A informática, ainda segundo Levy (1993, p.114), "faz parte do trabalho de reabsorção de um espaço-tempo social viscoso, de forte inércia, em proveito de uma reorganização permanente e em tempo real dos agenciamentos sociotécnicos: flexibilidade, fluxo tencionado, estoque zero, prazo zero".

A informação on-line tem toda uma linguagem própria. Ao apreender seu sentido o homem se percebe limitado ao espaço da fala com o outro e/ou alguns outros. Quando passa a dominar a escrita os níveis de apropriação crescem, assim como a expansão extraordinária que se completa com Gutenberg ao inventar a imprensa. Fica patente, porém que, em todos os tempos, as tentativas de apropriação dos instrumentos se circunscrevem a determinados segmentos sociais que, com o passar do tempo,

Educ. e Filos., Uberlândia, v. 20, n. 39, p. 13-38, jan./jun. 2006 
trabalham no sentido de aumentar o gap entre as beiradas de um fosso que aos poucos se transforma em abismo.

Observadas de diferentes ângulos, evidencia-se que as tecnologias de informação e de comunicação estão presentes no cotidiano da sociedade contemporânea, revolucionando as formas de apropriação dos conhecimentos. Segundo Kerckhove (1997, p.237) "como nômades telemáticos, libertamo-nos dos constrangimentos de uma coincidência histórica entre espaço e tempo e ganhamos o poder de estar em todos os lugares, sem sairmos do mesmo lugar". A temporalidade é rompida; entramos em contato com a descontinuidade, com o processo de digitalização, que transforma tudo em bytes, deixando para trás o mundo analógico, com seus tempos, sua maneira de pensar e de agir.

A revolução tecnológica imprime mudanças de natureza cultural, política, econômica e social "na chamada era das infosociedades" (MORAES, 1997, p.12), exigindo novas competências no mundo do trabalho, configurando a urgência de saberes compartilhados nas redes que abrem novas perspectivas quase segundo a segundo. Nessa linha de pensamento, a velocidade de acesso às informações possibilita avanços de ordem científica, cultural e tecnológica dos grupos sociais, podendo a escola desempenhar um papel significativo na familiarização dos alunos com o "mundo teleinfocomputrônico" (DREIFUSS, 1996).

Os computadores estão entrando na vida de pessoas de diferentes idades e pertencentes a diferentes segmentos sociais. Possibilidades extraordinárias advêm com os dispositivos telemáticos. Entram nas empresas, nos lares, nas escolas, em espaços destinados ao lazer, entre outros, introduzindo diferentes sensações em seus consumidores. Identificamos inicialmente o usuário desta máquina como um consumidor que se submete ao volume de propaganda que apregoa suas qualidades e virtudes, de forma agressiva, criando a necessidade de consumo, como só marqueteiro capitalista sabe fazer.

Sob a ótica de Marques (2003, p.68), no que se refere às linguagens articuladas pela máquina, que podem favorecer a comunicação:

Educ. e Filos., Uberlândia, v. 20, n. 39, p. 13-38, jan./jun. 2006. 
[...] importa percebermos a característica básica dessa outra forma de articulação de linguagens: a digitalização que insere no centro de um tecido eletrônico, em altíssima velocidade, as interfaces homem-máquina, ou os últimos envoltórios técnicos armados em redes em constante reconfiguração programável.

Assim, o computador, como recurso comunicacional, atrai um expressivo percentual de consumidores de tecnologia. Mal tivemos tempo de digerir o rádio, o telefone, a TV e estamos olhando pelo retrovisor a utilização de vídeos, do fax, do correio, etc... Nunca esteve tão atual a expressão que já caiu no gosto popular: "quando finalmente aprendi as respostas, mudaram as perguntas!" $\mathrm{O}$ computador é um produto que tende a se transformar em mais um eletrodoméstico do século XXI, com a propriedade de se tornar um "Grande Irmão" (ORWELL, 2004) ou fonte inesgotável de pesquisa, de agendamento de rotinas diárias, de comunicação e relacionamento. Um misto de desafio e insegurança toma conta desse usuário. Observando com atenção como essa cena acontece no mundo da educação, temos um quadro que muitas vezes lembra uma obra kafkiana, pelo inusitado de situações em que se desdobra.

Constatamos em congressos, seminários, palestras e videoconferências o abismo que se estabelece entre as vozes dos educadores, direcionando para as grandes transformações tecnológicas do mundo e a contrapartida, quando apresentam o material de sua apresentação, em transparências produzidas manualmente. Não são poucas as vezes em que somos obrigados a participar, por horas e horas, de um discurso que parece negar todos os recentes estudos sobre a capacidade de compreensão, apropriação de conhecimento e perspectiva dialógica, por meio do uso de dispositivos que conjugam os sentidos: ver, ouvir, falar.

Já na sala de aula, segundo Valente e Freire (2001) o uso do computador "tanto pode reforçar processos informacionais quanto criar condições para o aluno construir seu conhecimento". A formação de adultos/educadores pode assim ser realizada usando essa ferramenta, que permite a vivência do apreender 
continuadamente, apresentando possibilidades de se refletir na "práxis" do sujeito, ao integrar o computador à sua prática pedagógica.

Se visto como bem de consumo, estará sempre sob fortes luzes, já que se precisa implementar a venda e aquisição de novidades tecnológicas. O computador passa a fazer parte da categoria de invisibilidade quando passa a fazer parte da vida do ensinante e aprendente tal como faz o lápis, incluído na família das ferramentas indispensáveis na sala de aula, ou melhor, dizendo no ambiente escolar sem que se faça alarde do mesmo, no que pese estar também sub-utilizado na sua capacidade criativa e super-utilizado na sua "capacidade copiativa".

Adorno e Horkheimer (1985, p.40) apontam para o surgimento de uma indústria cultural, com capacidade de atingir as mais diferentes camadas sociais e as diferentes suscetibilidades, utilizando o que de mais sofisticado existe para sensibilizar olhos e ouvidos. Segundo eles, "o preço da dominação não é meramente a alienação dos homens com relação aos objetos dominados; com a coisificação do espírito, as próprias relações dos homens foram enfeitiçadas, inclusive a relação do indivíduo com ele mesmo".

A escola passa a mediar esta e outras questões, além de temas como tecnologia, conteúdos filosóficos que vão alicerçar diferentes procedimentos. É sabido que, entre seus alvos, está a preparação dos aprendentes para serem absorvidos no mercado, cujas leis são a cada dia mais exigentes, por ser uma época, em que o consumo e a efemeridade do produto a ser consumido integram tanto a esfera material, como na esfera humana.

O material - produto do processo de industrialização - e o sujeito, produto do sistema são descartáveis tendo em vista a voracidade do mercado. Assim, a escola que nem sempre primou pela ousadia de estar à frente da mudança, cada vez mais se confronta com um tempo que insiste em afastá-la do epicentro das inovações, reduzindo-a a ocupar o lugar de outsider, que perde o trem na estação, pois não correu o suficiente para alcançá-lo.

Incrementa-se o compromisso com a tecnologia, ressalvando o aparecimento de uma ordem tecnocrata, que aos poucos se 
insinua no discurso e na ação da escola. Os usos mecânicos, desprovidos de debate, diálogo e dialogia, dos equipamentos midiáticos nas instituições escolares serão inúmeras vezes referidos como fator de acomodação dos sujeitos ao sistema. É o discurso se afastando da realidade.

Ainda na formação de formadores, um passo prévio à construção do curso se faz necessário: identificar no sujeito um perfil dialógico, capaz de manter constante interatividade entre ensinante-aprendente, ou seja, vincular o espaço do saber com o respeito ao direito e dever de todos, saudável princípio democrático aplicável em todos os tempos.

A condição para estabelecer a relação entre as diferentes teorias, na figura de redes, vem do entendimento da especificidade deste tipo de aprender a aprender, que apresenta a educação online. A transmissão de conhecimento utiliza à exaustão a palavra escrita para a construção do conhecimento. Praticamente tudo gira em torno de material escrito, passando por livros, textos e inclusive grande quantidade de arquivos encontrados no entorno informático. O que vai estabelecer a diferença é o grau de interatividade estabelecido entre o educador-formador com o sujeito que está do outro lado da máquina. A partir dessa constatação, a construção de cursos on-line precisa avaliar o quanto o "diálogo dialógico" é capaz de manter a interatividade entre os envolvidos. O diálogo só se efetiva em um espaço democrático, que reconhece e valoriza "o aluno em sua inteligência e posicionamento sociocultural" (SILVA, 2002, p.200).

Na prática temos dois problemas básicos a serem enfrentados: "(a) professores e alunos estão constantemente em terrenos culturais diferentes e tem dificuldades consideráveis de erguer e atravessar pontes e (b) a adoção de uma nova postura obriga o docente a abandonar métodos, crenças e comportamentos tradicionais" (apud SILVA, 2002, p.201).

Diálogo não é um tema novo. A História apresenta fatos abomináveis toda vez que ele se faz ausente. Seria de se esperar que neste milênio, que já conta com mais de mil dias vivenciados, esse fosse apenas um tópico a ser confirmado no curriculum vitae

Educ. e Filos., Uberlândia, v. 20, n. 39, p. 13-38, jan./jun. 2006 
de cada educador. Assim, como não é o remédio para todos os males, tem sido usado de inúmeras maneiras para agregar o humano a um determinado contexto ou como processo a ser estudado por teorias de comunicação em psicologia, etc.

Para Bakhtin (1995, p.123):

[...] diálogo, no sentido estrito do termo, não constitui, é claro, senão uma das formas, é verdade que das mais importantes, de interação verbal. Mas pode-se compreender a palavra "diálogo" num sentido amplo, isto é, não apenas como a comunicação em voz alta, de pessoas colocadas face a face, mas toda comunicação verbal, de qualquer tipo que seja.

Identificar a importância das idéias de Bakhtin e Buber para este estudo é o nosso próximo passo e posteriormente seus pontos de convergência. "O sujeito bakhtiniano só pode ser compreendido ou estudado a partir das relações que promove com seu meio, já que as características humanas surgem da interação dialética entre o homem e seu meio sociocultural" (RAMAL, 2002, p.96). A relação entre o sujeito e o mundo, em verdade, é mediada todo o tempo pela linguagem; "a palavra é o fenômeno ideológico por excelência. A palavra não comporta nada que não esteja ligada a função de signo [...]. A palavra é o modo mais puro e sensível de relação social" (BAKHTIN, 1995, p.36).

O diálogo é em realidade uma inter-ação entre dois sujeitos concretos e aparentemente determinados em sua função comunicativa. "Todo Eu e Tu fala de encontro, pretende ser um diálogo e por isso padece com as insuficiências decorrentes de um estilo enigmático; como o próprio diálogo, que não pode ser impessoal, mas interpessoal, acontece em um clima de mistério" (BUBER, 1979, p. LXXIII). Assim, o relacionamento do EU não se dá com qualquer ser humano ou quem sabe, com alguém. $\mathrm{O}$ relacionamento se dá com um sujeito determinado, o TU.

Não se trata de jogo de palavras, Buber, inúmeras vezes, é anti-romântico na assertiva do reconhecimento do Outro, para ele 
"a palavra é referencial na medida que faz apelo ao locutor ou escritor" (BUBER 1979, p. LXXV), ou seja, ao reconhecer o OUTRO, ao legitimá-lo na sua alteridade, o confirma como o OUTRO do diálogo. Para que o diálogo se consuma, é fundamental, a existência do seu elemento constitutivo, a palavra. "Compreender é opor à palavra do locutor uma contra-palavra" (BAKHTIN, 1995, p.132).

A comunicação no espaço informático requer a compreensão por parte dos dialogantes de um curso, "é de certo modo, vencer as diferenças existentes entre dois códigos. Interpretar é aproximarse das coisas que a linguagem nomeia apesar das diferenças das línguas" (BUBER, 1979, p. LXXVI) e, ousadamente, acrescentaríamos, das linguagens. Só depois de ocorrida a compreensão de uma língua falada e escrita, se é capaz de procurar um similar no código já conhecido: "a significação pertence a uma palavra, enquanto traço de união entre interlocutores, isto é, ela só se realiza no processo de compreensão ativa e responsiva" (BAKHTIN, 1995, p.132), numa dimensão participativa.

Ainda segundo Silva (2002, p.158):

[...] participar é muito mais que responder sim ou não; é modificar [...] comunicar pressupõe recursão da emissão e recepção [...]o emissor [...] não propõe uma mensagem fechada, ao contrário, oferece informações em redes de conexões permitindo ao receptor ampla liberdade de associações e significações.

Eis que as idéias de Bakhtin e Buber convergem. Para Buber a relação EU-TU se constitui fundamentalmente por meio da palavra; "palavra da proximidade pela proximidade, resposta que precede a questão, palavra de responsabilidade pelo Outro, tornando possível para o Outro, toda a beleza e força da oferta" (ZUBEN, 2003 p.174). A comunicação é um ato eivado de filosofia de vida; está no desejo do sujeito de ser entendido pelo outro e vice-versa. Ao utilizar a palavra, supõe-se da capacidade intrínseca do sujeito em entendê-la, 
[...] palavra pela qual saio do meu EU em direção ao outro, palavra prenhe de reciprocidade, que ao ir em direção ao outro - TU - faz com que me recupere e me instale numa terra, [...] como se o afastamento de si mesmo fizesse o homem reaproximar de seu ser, agora transformado, livre do peso de sua identidade solitária (ZUBEN, 2003, p.175).

Dada a importância dessa ferramenta emancipatória, cabe possibilitar que o maior número de sujeitos tenha condições de aprofundar o que Bakhtin (FARACO, 2001, p.173) entende como diálogo "entre pessoas, entre textos, autores, escolas e vidas".

Esse estado dialogal se deve à construção do sistema lingüístico, a saber "sistema das formas fonéticas, gramaticais e lexicais da língua" (BAKHTIN, 1995, p.77). Trata-se de entender a relação da linguagem e o entorno, em que medida a pressão de fora para dentro e a ideologia determinam a atividade mental, entre outros. À medida que essa linguagem é codificada, passa a ser escrita e se torna uma "mais valia" para o sujeito diferenciando-os em alfabetizados e analfabetos. Essa é a dura realidade do século XXI: alfabetização mecânica, que se torna significativa à medida que se torna necessária.

Entende-se, assim, a necessidade de educadores se alfabetizarem não só em uma, mas em diferentes linguagens, para uma prática pedagógica que já não se preocupa tanto em explicar o que não foi aprendido. A via de acesso é a dialogia ao invés de monologia, os procedimentos levam à interatividade, contribuindo desta forma para a formação do sujeito cidadão.

Continuando nessa linha de raciocínio, a polifonia de diálogos encaminha reflexões, a partir da realidade, no sentido de saber fazer e o saber compreender. Há uma encruzilhada onde se encontram Habermas, Bakhtin, Buber, Shön e Freire e que dificilmente um educador-formador que vá se envolver com a EAD pode abrir mão de conhecer, refletir e praticar. 


\section{Breves considerações finais}

Descortinam se mais possibilidades ou mais desafios? Não há como quantificar.

O desafio é não desistir de nossos propósitos, tendo em vista que há saberes fascinantes, que abrem horizontes para novas concepções e diferentes práticas. Os entraves são evidentes. Sua superação é possível na medida que a formação de formadores estiver comprometida com as referencias básicas, a saber: diálogo dialógico e reflexão. Nessa perspectiva, pode-se vislumbrar a criação de novas alternativas nesse universo ainda pouco explorado dos cursos on-line.

\section{Referências}

ABAGGNANO, N. Dicionário de Filosofia. São Paulo; Martins Fontes, 2000.

ADORNO, Theodor W. Educação e emancipação. Rio de Janeiro. Paz e Terra: 1995

ADORNO, Theodor e HORKHEIMER, Max. Dialética do esclarecimento. Rio de Janeiro: Zahar Editores, 1985.

ALARCÃO, Isabel (Org.). Escola reflexiva e nova racionalidade. Porto Alegre: Artmed Editora, 2001.

ARAGÃO, L. M. de C. Razão comunicativa e teoria social crítica em Jurgen Habermas. Rio de Janeiro: Tempo Brasileiro, 1992.

BAKHTIN, M. Marxismo e filosofia da linguagem. São Paulo. Editora Hucitec, 1995.

1992.

Estética da criação verbal. São Paulo: Martins Fontes,

Educ. e Filos., Uberlândia, v. 20, n. 39, p. 13-38, jan./jun. 2006 
BENJAMIN, W. Reflexões: a criança, o brinquedo, a educação. São Paulo: Summus, 1984.

BOURDIEU, P. A reprodução. Rio de Janeiro: Francisco Alves, 1992.

BUBER, Martin. EU e TU. São Paulo: Cortez e Moraes 1979.

DREIFUSS, René. A época das perplexidades. Petrópolis: Vozes,1996.

FARACO, C. \& TEZZA, C. (Org). Diálogos com Bakhtin. Curitiba: Ed.da UFPR, 2001.

FREITAG, B. O conflito moral. In: Revista Tempo Brasileiro, v.1, n.1, Rio de Janeiro: Tempo Brasileiro, 1962.

FREIRE, P. Educação como prática da liberdade. Rio de Janeiro: Paz e Terra, 1979.

. Educação e mudança. Rio de Janeiro: Paz e Terra, 1981.

1996.

. Pedagogia da autonomia. Rio de Janeiro: Paz e Terra,

HABERMAS, Jurgen. Escritos sobre moralidad y eticidad. Barcelona: Paidós, 1991.

70,1968

Ciência e técnica como ideología. Portugal: Edições

. O discurso filosófico da modernidade. Porto/Portugal:

Publicações D. Quixote, 1990.

KERCKHOVE, D. A pele e a cultura. Uma investigação sobre a nova realidade eletrônica. Lisboa: Relógio D’Agua, 1997.

LEVY, P. Cibercultura. São Paulo: Editora 34, 1999.

Educ. e Filos., Uberlândia, v. 20, n. 39, p. 13-38, jan./jun. 2006.

36 
1993.

As tecnologias da inteligência. São Paulo: Editora 34,

Inteligência coletiva: por uma antropologia do ciberespaço São Paulo: Loyola, 1998.

MARQUES, M. O. A escola no computador: linguagens rearticuladas, educação outra. Ijuí: Editora Unijuí, 2003.

MORAES, D. de (Org.). Globalização, mídia e cultura contemporânea. Campo Grande: Letra Livre, 1997.

PAPERT, S. A máquina das crianças: repensando a escola na Era da Informática. Porto Alegre: Artes Médicas, 1994.

ORWELL, George. 1984. São Paulo: Companhia Editora Nacional, 1957.

RAMAL, A C. Educação na cibercultura: hipertextualidade, leitura, escrita e aprendizagem. Porto Alegre: Artmed, 2002.

SAMPAIO, M. \& LEITE L. A alfabetização tecnológica do professor. Petrópolis: Vozes 1999.

SHON, D. Educando o profissional reflexivo. Porto Alegre: Ed. Artmed, 2000.

SILVA, Marco. Sala de aula interativa. Rio de Janeiro: Quartet, 2002.

SILVA, E. T. (Org.). A leitura nos oceanos da Internet. São Paulo: Cortez, 2003.

VALENTE, J. A. e FREIRE, F. P. Aprendendo para a vida: os computadores na sala de aula. São Paulo: Cortez, 2001. 
ZUBEN, N. A. von. Martin Buber: cumplicidade e diálogo. São Paulo: EDUSC, 2003.

Data de Registro 05/08/05

Data de Aceite 26/09/05

Educ. e Filos., Uberlândia, v. 20, n. 39, p. 13-38, jan./jun. 2006. 